\title{
Effect of fibre loading on the physical, mechanical and thermal properties of sugar palm fibre reinforced vinyl ester composites
}

\begin{abstract}
In this research, the variation of mechanical properties (i.e. tensile, flexural and impact strength), physical properties (i.e. water absorption, SEM and thickness swelling) and thermal properties of sugar palm fibre reinforced vinyl ester composites were investigated. The composites with different fibre content, which are $10 \mathrm{wt} . \%, 20 \mathrm{wt} . \%, 30 \mathrm{wt} . \%$ and $40 \mathrm{wt} . \%$, were prepared. The additions of sugar palm fibres to vinyl ester reduce tensile and flexural strength of the composites, which are 25.1 MPa (10 wt.\%), 12.5 MPa (20 wt.\%), 9.7 MPa (30 wt.\%) and 6.1 $\mathrm{MPa}(40 \mathrm{wt} . \%)$ for tensile strength, while for flexural strength, the results recorded 48.5 MPa, 24 MPa, 18.8 $\mathrm{MPa}$ and 2.5 $\mathrm{MPa}$ for $10 \mathrm{wt} . \%, 20 \mathrm{wt} . \%$, $30 \mathrm{wt} . \%$ and 40 wt. $\%$. However, sugar palm fibres improve impact strength of the composites especially at 30 wt $\%$ with $5.4 \mathrm{~kJ} / \mathrm{m}^{2}$. The addition of sugar palm fibres also raise the water absorption and thickness swelling of the composites as the presence of fibres in the composites increase water retained in the composites. Besides that, thermal stability of the composites also reduces by the addition of the sugar palm fibres that shows the onset temperature of thermal degradation of 10 wt. $\%$ was at $270.83{ }^{\circ} \mathrm{C}$, while $40 \mathrm{wt} . \%$ was at $196.67{ }^{\circ} \mathrm{C}$.
\end{abstract}

Keyword: Sugar palm fibres; Vinyl ester composites; Physical properties; Mechanical properties; Thermal properties 